\title{
Optimal rail-road container terminal locations on the European network
}

\author{
S. Limbourg *, B. Jourquin \\ Louvain School of Management, FUCaM, Mons Campus, 151 Ch. de Binche, B-7000 Mons, Belgium
}

\section{A R T I C L E I N F O}

\section{Article history:}

Received 26 May 2008

Received in revised form 27 November 2008

Accepted 6 December 2008

Available online $\mathrm{xxxx}$

\section{Keywords:}

Location

Terminals

Hub-and-spoke

Network

Intermodal

Transport

\begin{abstract}
A B S T R A C T
The European transport policy has focused on sustainable transport solutions, among which intermodal transport is a key player. However, its efficiency is strongly dependent on the location of the container terminals. In this paper, a set of estimated potential locations is used as input for an iterative procedure based on the $p$-hub median problem that takes the variation in trans-shipment costs according to the number of trans-shipped containers into account. The final results are the optimal locations for European transfer terminals embedded in a hub-and-spoke network.
\end{abstract}

(c) 2008 Elsevier Ltd. All rights reserved.

\section{Introduction}

The success of road transport results in ever-worsening congestion and more environmental problems. That is why one of the objectives of the European Common Transport Policy is to restore the balance between modes of transport and to develop intermodality. To promote this, the Commission has launched the Marco Polo programme, the objective of which is to transfer 12 bn ton-km/year from road to other modes of transportation in Phase 1, rising to $20.5 \mathrm{bn}$ ton-km/year in Phase II.

A review of intermodal rail-road transport related problems can be found in Bontekoning et al. (2004). Among the identified topologies, this paper is concerned with rail-road combined transport using terminals embedded in a hub-and-spoke rail network. This kind of topology is supposed to reduce transportation costs by consolidating shipments at the hubs. The efficiency of such a network depends on the location of the hubs and the problem is thus to find the optimal hub locations and to allocate the remaining nodes to these hubs. This problem is known as the $p$-hub median problem.

Among recent papers, Jeong et al. (2007) focused their research on freight transport by rail between ten European countries. Their paper addresses the problem of a planner who has to identify the best combination of routes, frequencies, volume and length of trains. Racunica and Wynter (2005) also considered a rail hub-and-spoke network, but from a more theoretical point of view, using recent findings on the polyhedral properties of this class of problems.

The optimal location problem for container transfer terminals embedded in a hub-and-spoke network is not easy to solve for networks containing several thousands of nodes, as the number of possible locations rapidly becomes too large to be taken as input by exact optimal location models. They thus have to start with a subset of nodes that can be considered as good potential locations.

\footnotetext{
* Corresponding author. Tel.: +32 65 323293; fax: +32 6531569.

E-mail addresses: sabine.limbourg@fucam.ac.be (S. Limbourg), bart.jourquin@fucam.ac.be (B. Jourquin).
} 
In a some papers (see, for instance, Macharis, 2004), the potential locations are determined using common-sense and a lot of information collected on the field. Three systematic approaches based on the locations of the network nodes are presented in Arnold (2002) and Arnold et al. (2002, 2004). Spatial aggregation of demand nodes can also be used to reduce the size of location problem. Limbourg and Jourquin (2007) applied the $p$-HMP to a set of potential locations obtained by both spatial aggregation of demand nodes using hierarchical clustering methods and by a flow-based approach which takes the flows of commodities and their geographic spread into account. They showed that the latest method gives better results and that is why it is retained in this paper to determine a set of potential locations that will be used as input for an adapted $p$-hub median problem formulation.

The main contribution of this paper is to propose an iterative procedure based on both the $p$-hub median problem and the multi-modal assignment problem. Moreover, the objective function of our $p$-hub median formulation includes the costs for preand post-haulages by road, trans-shipment (according to the number of handled containers into account) and rail haulage.

In the $p$-hub median problem, the total demand is assigned to the hubs. In this paper however, the demand can be assigned over all the transportation modes, with the possibility (but not the obligation) of using the trans-shipment facilities.

The $p$-hub median problem is then further solved again with updated trans-shipment costs based on the estimated flow at each terminal. This procedure is repeated until the relative difference in trans-shipment costs between two iterations is smaller than a given threshold, set to $1 \%$ in our case.

The definition of the problem to be solved and the inputs needed are explained in Section 2, while Section 3 presents the proposed methodology. Finally, an application that considers multi-modal transport over the whole trans-European network, taking into account existing or new hubs is illustrated in Section 4.

Another application finally compares and discusses the optimal locations obtained by our method to those described by Ballis (2002) and to Jeong et al.'s (2007).

\section{The p-hub location problem}

In the standard multiple-hub network problem (see O'Kelly and Miller (1994) for the different classes of problems), three constraints are traditionally identified: it is assumed that all the hubs are connected directly to each other, that there is no direct connection between non-hub nodes, and that the non-hub nodes are connected to a single hub. The inter-hub links consolidate the total flow coming from the origin hub (or any of its spoke nodes) to the destination hub (or any of its spoke nodes). The location of the hubs must be chosen from the set of nodes, $N$, considered as potential locations and the objective is to minimise the total transportation cost.

The $p$-hub median problem ( $p$-HMP) was first formulated as a quadratic integer program by O'Kelly (1987). Campbell (1994) formulated this problem as a mixed integer linear programming problem. Refinements were further proposed by Campbell (1996), Skorin-Kapov and O'Kelly (1996) and O'Kelly et al. (1996).

This problem is hard to solve, opening the way to heuristics (see for instance O'Kelly (1987), Aykin (1990), Klincewicz (1991), Campbell (1996)) and metaheuristics (Smith et al., 1996; Ernst et Krishnamoorthy, 1996; Klincewicz, 1992; Skorin-Kapov and Skorin-Kapov, 1994). Approaches using upper and lower bounds were also proposed O'Kelly, 1992; O’Kelly et al., 1995; Skorin-Kapov et al., 1996). Finally a number of methods that are able to find the optimal solution for problems of limited size can be found in Skorin-Kapov et al. (1996), O'Kelly et al. (1996), and Ernst and Krishnamoorthy (1996).

Our model is based on the formulation proposed in the latest paper, in which $Y_{k m}^{i}$ defines the total flow of commodities $i$ (i.e., traffic emanating from node $i$ ) that is routed through hubs $k$ and $m$. If the total flow from node $i$ is denoted by $O_{i}=\sum_{j \in N} W_{i j}$ and the total flow to node $i$ is denoted by $D_{i}=\sum_{j \in N} W_{j i}$, the formulation becomes:

\section{Inputs:}

$p=$ number of hubs to be opened

$W_{i j}=$ flow from origin $i$ to destination $j$

$C_{i j}^{k m}=$ unit cost between origin $i$ and estination $j$ via the hubs located at nodes $k$ and $m$

$$
=\chi C_{i k}+\alpha C_{k m}+\delta C_{m j}
$$

where $\chi$ is the relative cost of pre-haulage; $\alpha$ is the inter-hub discount $(0 \leqslant \alpha \leqslant 1)$; $\delta$ is the relative cost of post-haulage; and $C_{i j}$ is unit travel cost between origin $i$ and destination $j$.

Decision variables:

$$
\begin{aligned}
& X_{i j}=1 \text { if node } i \text { is connected to a hub located at node } j \forall i, \quad j \in N \\
& 0 \text { if not } \\
& Y_{k m}^{i} \geqslant 0 \forall i, \quad k, m \in N
\end{aligned}
$$

Minimise:

$$
\sum_{i \in N} \sum_{k \in N} C_{i k} X_{i k}\left(\chi O_{i}+\delta D_{i}\right)+\sum_{i \in N} \sum_{k \in N} \sum_{m \in N} \alpha C_{k m} Y_{k m}^{i}
$$


Subject to:

$$
\begin{aligned}
& \sum_{x \in N} X_{k k}=p \\
& \sum_{k \in N}=1 \quad \forall i \in N \\
& X_{i k} \leqslant X_{k k} \quad \forall i, k \in N \\
& \sum_{m \in N} Y_{k m}^{i}-\sum_{m \in N} Y_{m k}^{i}=O_{i} X_{i k}-\sum_{j \in N} W_{i j} X_{j k} \quad \forall i, k \in N \\
& X_{i j} \in\{0,1\} \quad \forall i, j \in N \\
& Y_{k m}^{i} \geqslant 0 \quad \forall i, k, m \in N
\end{aligned}
$$

The objective function (1) minimises the total transportation cost on the system. Constraint (1.1) stipulates that exactly $p$ hubs should be used. Taken together, Eqs. (1.2) and (1.5) ensure that each node is allocated to a single hub and that a hub node cannot be allocated to another hub. Eq. (1.3) prevents allocations to non-hub nodes. Eq. (1.4) is the divergence equation for commodity $i$ at node $k$ in a complete graph, where the demand and supply at the nodes is determined by the allocations $X_{i k}$. Constraints (1.5) ensure that $X_{i j}$ is binary. This problem involves $\left(N^{3}+N^{2}\right)$ variables and requires $\left(1+N+2 N^{2}\right)$ linear constraints.

Each $(i, j)$ pair in a $p$-HMP is analogous to a demand point in a $p$-median problem $(p$-MP) in which the demand nodes are assigned to the nearest facilities. As it may not be optimal to assign the demand nodes to their nearest hub, the $p$-HMP relaxes this constraint.

\subsection{Rail-road transport}

The Recordit (REal COst Reduction of Door-to-Door Intermodal Transport, 2002) European research program defined and validated a methodology for estimating the costs of intermodal freight transport in Europe. Recordit also compared the costs of intermodal and road-only solutions. The methodology used to collect the data and to compute the costs was based on the description of the intermodal chain, defined as a sequence of activities. The estimations of the costs in the model presented in this paper are essentially based on Recordit.

The PINE report (Prospective Customers of Inland Navigation Within the Enlarged Europe Report, 2004) was also used to refine the costs for barge transport. Data on road transport published by the French Road National Committee (CNR, 2007) were also considered. Finally, railway costs were validated on the basis of a report of the Ministry for Mobility in the Netherlands (Vervoort and Split (2005)).

The usage distribution between containers sizes is about $60 \%$ for $40^{\prime}$ and $40 \%$ for $20^{\prime}$ boxes. Knowing that the average net weight of a TEU is about 15 or 16 tons (International Union of combined Road-Rail transport companies (UIRR)), the (un)loading costs are estimated to $1.297 € / \mathrm{t}$. Using the same sources, the costs for the different haulages are:

- $0.105 € /$ t for pre- and post-haulage;

- $0.072 € / \mathrm{t}$ for road haulage;

- $0.042 € / \mathrm{t}$ for rail haulage;

- $0.014 € / \mathrm{t}$ for barge haulage.

Assuming a $10 \%$ cost reduction for inter-hub rail transport resulting from economies of scale and that $T_{i}$ is the trans-shipment cost of the hub located at $i, \chi=\delta=\frac{0.105}{0.072}=1.458, \alpha=\frac{0.90 * 0.042}{0.072}=0.525$ the objective function (1) becomes:

$$
\sum_{i \in N} \sum_{k \in N}\left(1.458 C_{i k}+T_{k}\right) X_{i k}\left(O_{i}+D_{i}\right)+\sum_{i \in N} \sum_{k \in N} \sum_{m \in N} 0.525 C_{k m} Y_{k m}^{i}
$$

In order to integrate the variation of the trans-shipment costs according the number of handled TEUs, a logarithmic regression was performed on the results of the various trans-shipment costs obtained by Ballis and Golias (2002) for different terminal configurations. These terminals handle between 25,000 and 300,000 intermodal transport units (ITU) per year. If $T(n)$ is the trans-shipment cost and $n$ the number of ITUs trans-shipped, $T(n)=-12.163 \ln (n)+180.26$ with $r^{2}=0.96$. A lower limit is set at $2 € /$ ton and an upper limit is set to $5 € /$ ton to remain in line with the Recordit and (ECMT, 1998) reports.

\subsection{Determining the demand}

We used the origin-destination (OD) matrices for the year 2000, produced by NEA transport research and training. The matrices give information about the type of commodity being transported, classified according to the standard goods classification for transport statistics/revised (NST/R chapters). Only the figures for NST/R chapter 9, containing the demand for containers amongst other manufactured products, were taken into account in the model. The database contains region-toregion relations at the NUTS 2 (Nomenclature of Territorial Units for Statistics) level, for the area of the EU25, plus Norway and Switzerland. 
A centroïd for each NUTS 2 region was located on our network. As several important cities of different sizes can be found inside a same region, each centroïd was placed at the centre of the most inhabited city of the region instead of at the geographic gravity centre. These centroïds are taken as the origins or destinations for the commodities. The assignment of the demand between these centroïds is performed using the algorithm presented in Jourquin (2006) that spreads the flow over several alternative routes and transportation modes on a multi-modal network.

The use of centroïds in rather large regions such as NUTS 2 regions can lead to some errors due to the level of aggregation. Indeed, NUTS 2 regions are irregular in shapes and sizes and there is a strong national effect as some countries have adopted larger NUTS 2 regions that others. The interested reader can refer to Limbourg (2007), in which a complete discussion of the problem and estimations of the possible errors that can be induced by it can be found.

In order not to disrupt the results with origin-destination pairs which are not concerned by combined transport, only the pairs separated by at least $300 \mathrm{~km}$ are taken into account. Indeed, the distance for pre- and post-haulages are often estimated to be $50 \mathrm{~km}$ (see for instance the European Conference of Ministers of Transport (1998) or Recordit, 2002). Moreover, if $d$ is the distance between the two terminals, if the trans-shipment costs are set to their lower limit and if the other operation costs are those presented in Section 2.1, the costs for combined transport and road-only transport are equal if: $100 * 0.105+d * 0.042+2 * 2=(d+100) * 0.072$.

As a result, intermodal trips should be longer than $343 \mathrm{~km}$.

The European Conference of Ministers of Transport (1998) also estimates that the shortest distance over which combined transport is competitive is $300 \mathrm{~km}$. Finally, according to the UIRR (International Union of combined Road-Rail Transport companies) statistics (2000), 92\% of the intermodal transport units (ITU) are used on trips that are longer than $300 \mathrm{~km}$. For all this reasons, the demand for shorter distances was left out of our matrices.

\subsection{Setting up the network}

The network model was developed using a software called NODUS which was developed at the "Group Transport \& Mobility" (GTM) of the Catholic University of Mons (Belgium). It is a G.I.S. (geographic information system) based software designed for analysing multi-modal and inter-modal freight transport with all their interface operations. It is also spatially referenced and based on ESRI ArcInfo shape files, making it compatible with most widespread GIS tools. Nodus uses BBN Technologies' OpenMap ${ }^{\mathrm{TM}}$ (www.openmap.org) package, that is an Open Source JavaBeans ${ }^{\mathrm{TM}}$ (java.sun.com) based programmer's toolkit, providing the means to allow users to see and manipulate various geospatial information.

The railway and road networks were taken from the digital chart of the World (DCW) and updated. The DCW is an Environmental Systems Research Institute, Inc. product originally developed for the US Defense Mapping Agency (DMA) using DMA data. The inland waterway network was digitised at our research lab. The borders of the NUTS 2 regions were provided by Geophysical Instrument Supply Co. (GISCO).

All these separate layers were connected using "connectors" from each centroïd to each modal layer located not further than the average radius of the considered regions, so about $100 \mathrm{~km}$. These connectors have an average length of $4.66 \mathrm{~km}$ for roads, $3.23 \mathrm{~km}$ for railways and $32 \mathrm{~km}$ for waterways, with respective standard deviations of 9.95, 6.34 and 38.85. The complete set of layers can be considered as a geographical graph, of about 110,000 edges and 90,000 vertices.

\subsection{Using flows to determine a set of potential locations}

Spatial aggregation of demand nodes is often used to reduce the size of location problems, but aggregation also introduces errors in the solutions. Different aggregation errors are discussed in Current and Schilling (1987), who also give methods to reduce them. Most of the relevant literature concerns the $p$-median or covering problem: Casillas (1987), Current et al. (1987, 1990), Francis et al. (1996, 1999), Goodchild (1979), Plastria (2001) and Zhao and Batta (1999, 2000).

As specified in the introduction of this paper, Limbourg and Jourquin (2007) applied the $p$-HMP to a set of potential locations obtained both by spatial aggregation of demand nodes using hierarchical clustering methods and by a flow-based approach, showing that the latest approach was to be preferred. Indeed, the total transportation cost on the system appeared to be systematically lower with the flow-based method for all the configurations that were tested. This can be considered as an advantage when the objective is to maximise the efficiency of the transport system.

In order to consolidate the flows which can be spread over different itineraries in the same corridor for same or different transportation modes, the flow-based method starts with an all-or-nothing assignment on the road network, which computes the cheapest path between each origin-destination pair and assigns all the trade flow to this single route. The result of this first assignment is presented in Fig. 1.

Different terminal classifications (Bowersox et al., 1986; Terminet, 1996, 1997a,b; Wiegmans et al., 1999; Wiegmans, 2003; Ballis, 2002) can help us to specify the type of terminal to be considered in this paper. The largest terminals (in terms of size and volume) have maritime connections and are located in ports such as Rotterdam, Antwerp, Hamburg, Le Havre, Marseille or Algeciras. They can be referred to as "XXL", "XL" or "consolidation" terminals. The shipment sizes that are handled in these facilities are large enough to fully load trains or barges, without any further consolidation.

The smallest terminals are "M", "S", "distribution" or "hinterland" terminals. They are also sometimes referred to as national or regional terminals. They need a line or a collection/distribution consolidation network topology for the commodities being transported. 


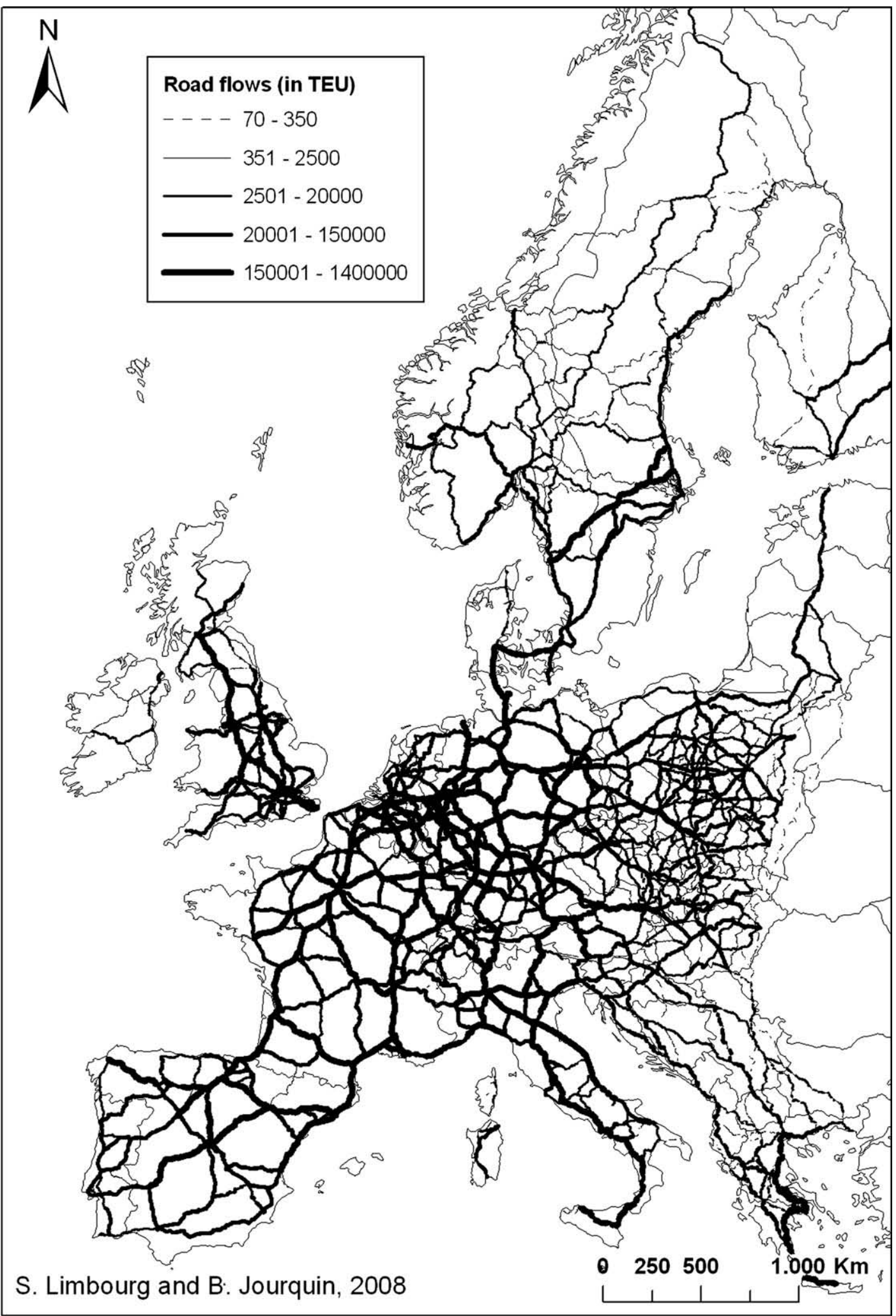

Fig. 1. Consolidated flow on the road network. 


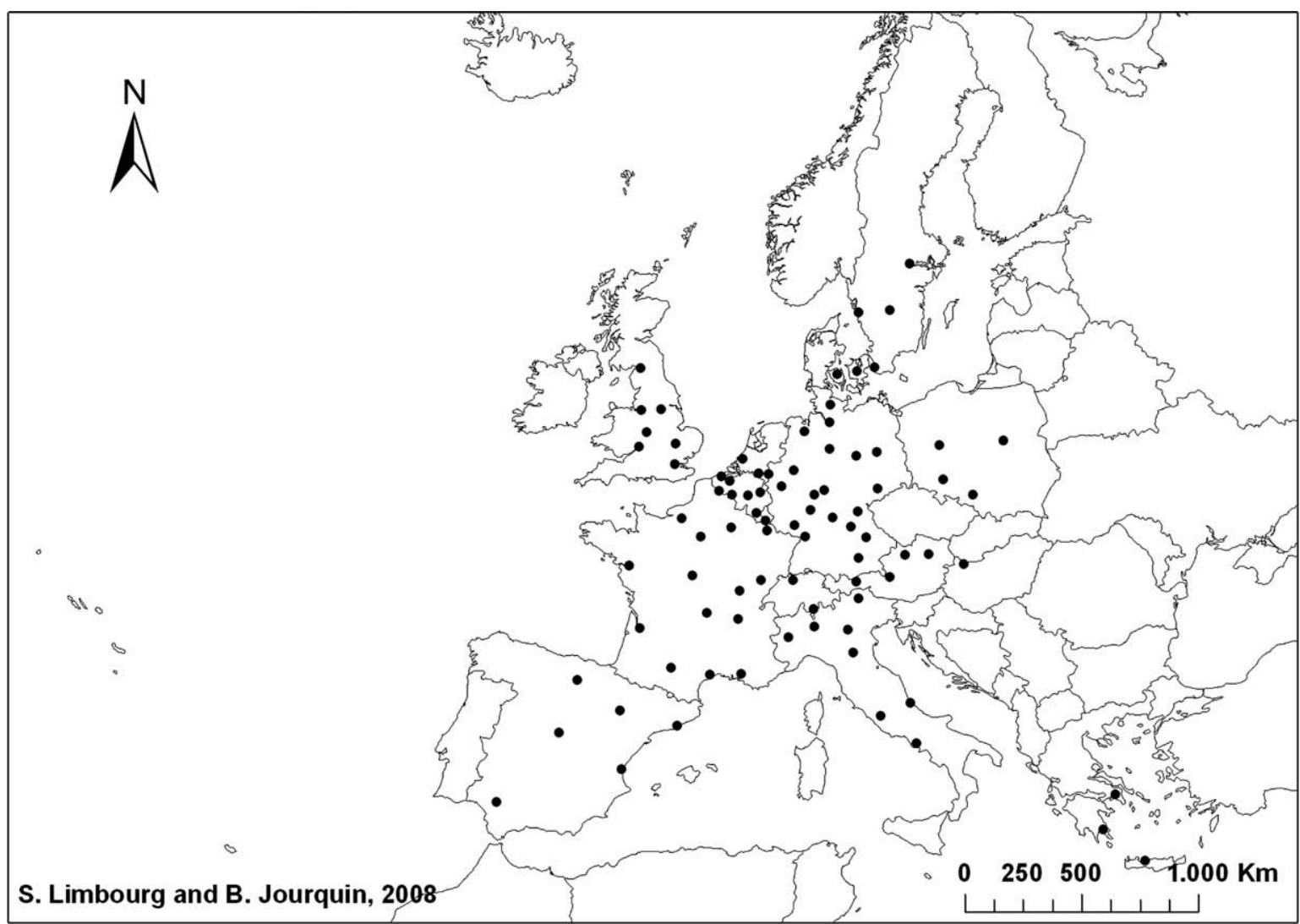

Fig. 2. Set of identified good potential locations.

Finally, the "L" or "transfer" terminals are mid-size facilities mostly devoted to trans-shipment operations for continental freight flows. These terminals are embedded in a hub-and-spoke network and are those which are referred to in this paper. They will be called "hubs" in the text. According to Ballis (2002), hubs are located in Metz, Villeneuve St. George (Paris), Schaerbeek (Brussels), Cologne, Hanover and Mannheim (i.e. in the North of Europe). Moreover Ballis points out that a hub near Milan would be useful.

Wiegmans (2003) estimates that the annual volume for this kind of terminals must be at least 100,000 twenty-foot equivalent units (TEU). A selection of potential locations is thus performed by retaining the nodes along which the consolidated flow is higher than a given threshold which impact will be discussed later. The resulting set of this first selection can be reduced by retaining only the nodes that are closer than $5 \mathrm{~km}$ from the railway network.

This set of nodes is however still rather large, mainly because many of them are close to each other, having similar characteristics (chain effect). At the micro or regional level, these nodes may be very different (availability of ground surface for instance). However, such considerations are less important at the macro European level where it is important to know where it would be helpful to locate a terminal. For this reason, only the node with the largest volume of flow in a given NUTS 2 region was kept (Fig. 2).

\section{Methodology}

\subsection{Reference scenario}

A geographical representation of a transportation network does not provide an adequate basis for detailed analyses of transport operations, as the same infrastructure (link or node) can be used in different ways. To solve this problem, the idea, initially proposed by Harker (1987) and Crainic et al. (1990), is to create a virtual link with specific costs for each particular use of an infrastructure network. The concept of super-networks described by Sheffi (1985) that proposes "transfer" links between modal networks provides a somewhat similar framework.

Jourquin and Beuthe (1996) discussed a methodology and an algorithm that create, in a systematic and automatic way, a complete virtual network with all its virtual links corresponding to different possible operations for every real link or node of a geographic network. Tavasszy (1996) also discussed virtual networks and the software that implements them. In this ap- 
Table 1

Global fit of the network model.

\begin{tabular}{|c|c|c|c|c|}
\hline & \multicolumn{2}{|l|}{ Tons } & \multicolumn{2}{|c|}{ Tons-kilometres } \\
\hline & Data (\%) & Model (\%) & Data (\%) & Model (\%) \\
\hline Waterways & 1.73 & 1.50 & 1.96 & 1.83 \\
\hline Rail & 13.55 & 14.17 & 15.10 & 15.12 \\
\hline Road & 84.72 & 84.33 & 82.94 & 83.05 \\
\hline
\end{tabular}

proach, both the modal choice and the assignment steps of the classical four-stage approach (in which generation, distribution, modal-split and assignment are treated as separate steps) are performed at the same time.

It appears (Jourquin and Limbourg, 2006), that equilibrium assignment procedures, which take capacity constrains into account, are unable to capture modal and route behaviours when they are applied to large scale networks such as the transEuropean multi-modal freight network. This is essentially due to the fact that equilibrium models are only efficient at a local level where congestion (or at least heavy traffic) is observed. As origin-destination matrices for long distance transport are often available on a yearly basis only, it is difficult to estimate what happens during the peak hours. Even more problematic is the fact that long distance transport last several hours, or even days, and it is not possible, with static models, to know where a vehicle is located at any given moment.

Congestion can however not be ignored. As container terminals are mostly located nearby urban areas and that pre- and post-haulages participate to the local traffic, the average speed on the local road network around the cities was lowered to correspond to the observed average speed (Stratec et al., 1999) in congested areas.

Last but not least, the demand at European level is often available only at the NUTS 2 level. At this level of aggregation, it is not realistic to assume that only one route between each OD pair is used. Therefore a multi-flow algorithm that ensures that the computed set of paths both contains different itineraries and uses different transportation modes is required. The retained method (Jourquin, 2006) spreads the flow over different realistic paths according to their relative weights in the set of alternative routes.

The results (Table 1) for the trans-European network clearly show that it is possible to obtain a globally calibrated model on both the transported quantities and the flows expressed in ton-km, using an assignment on a virtual network, without an explicit modal-split module. This first assignment represents the reference scenario that will be used later in this paper.

\subsection{Hub-and-spoke network design}

As outlined in Section 2.4, an all-or-nothing assignment of the OD matrix is firstly performed on the road network to select the potential locations. The results are used as input to a $p$-HMP to obtain $p$ optimal locations. Once the optimal locations have been determined, they are integrated into the network. As they are located on the road network, connectors to the closest rail node are created where needed. Then, the inter-hub railway network is identified, choosing the fastest railway route between each pair of terminals, creating a hub-and-spoke network that will further be used to model intermodal transport.

\subsection{Combined transport modelling}

In order to distinguish pre- and post-haulages and truck-only transport, three different road transportation means are considered: the first is for truck-only transport, the second for pre-haulage and the third for post-haulage. For rail transport, two means are considered: one for traditional rail transport and another that corresponds to the rail part of combined transport. There is no unloading associated with pre-haulage and no loading associated with post-haulage by trucks: these two means must thus be combined with the rail part of a combined transport trip to model intermodal transport.

\subsection{Assignment on a network where combined transport is allowed}

Once the combined transport has been modelled, a new assignment is performed, during which trans-shipments are made possible at the optimally located terminals. The demand can be assigned over all the transportation modes, with the possibility (but not the obligation) of using the trans-shipment facilities. Combined transport is thus considered as one possible transport solutions among others, and the three constraints of the $p$-HMP (see Section 2) are thus relaxed at this stage of the model.

\subsection{Iterative procedure}

To take the variation of the trans-shipment costs according the number of TEUs trans-shipped into account, an iterative procedure is needed. In order to estimate the trans-shipment cost of each facility $\left(T_{k}^{0} \forall k \in N\right)$, an assignment during which all the potential locations are considered as terminals is performed. After that, the following algorithm is implemented: 
1. $\mathrm{n}=0$,

2. minimise the objective function (2),

3. create the hub-and-spoke network,

4. assign on the network,

5. $\mathrm{n}=\mathrm{n}+1$,

6. determine the flows, $F_{k}^{n}$, trans-shipped at hub k,

7. compute the trans-shipment costs according to the flows $T_{k}\left(F_{k}^{n}\right)$,

8. $T_{k}^{n}=\left(T_{k}^{n-1}+T_{k}\left(F_{k}^{n}\right)\right) / 2$,

9. if $\exists k \in N: T_{k}^{n}\left(F_{k}^{n}\right)>T_{k}^{n-1}\left(F_{k}^{n-1}\right)$ go to Step 2,

10. if $\exists k \in N: \frac{T_{k}^{n}\left(F_{k}^{n}\right)-T_{k}^{n-1}\left(F_{k}^{n-1}\right)}{T_{k}^{n}\left(F_{k}^{n}\right)}>0.01$ go to Step 4 ,

11. stop.

\section{Results}

\subsection{Sensitivity of the model to some hypotheses}

\subsubsection{Sensitivity to the set of potential locations}

As explained in Section 2.4., the potential locations are dependent of the consolidated flow thresholds. To illustrate this, Table 2 gives the optimal locations obtained for a number of hubs varying from 2 to 10 and for minimum flow thresholds varying from 150,000 TEU (resulting in 33 potential locations) to 50,000 TEU (85 potential locations). Five configurations (for $p=3,4,5,9$ and 10) remain unchanged when the 50,000 or the 75,000 TEU threshold are used, and two ( $p=3$ and 10) when the 100,000 TEU threshold is considered. Except for the 150,000 TEU threshold case, all the configurations with ten hubs remain unchanged.

Fig. 3 represents the evolution of the ratio of the total transportation cost for a configuration with $p$-hubs, $C_{p}$, to the total cost of the reference scenario, $C$.

As expected, this total cost decreases with the threshold. It is worthwhile to note that the configurations obtained for a same number of hubs, $p$, are very similar in cost, except for the 150,000 TEU threshold case. This is due to the fact that London, identified as optimal location in the other cases, is missing in the set of potential locations for this threshold.

Fig. 4 illustrates the variation of the ton-km transported by road for the all these configurations. Note that for some networks with two or three hubs, the amount of bn ton-km/yr by road increases. A closer look to one of these two-hub configurations (London and Paris) shows that 1.46 bn ton-km/yr are transferred from road to rail but 2.08 bn ton-km/yr are needed for pre- and post-haulages. Such an optimal configuration could therefore very well not appear if the external costs for road transport were internalised.

In the next sections, all the presented analysis will be based on the 50,0000 minimum flow threshold, which results in the largest set of potential locations.

\subsubsection{Sensitivity to economies of scale on the inter-hub network}

The economy of scale that can be achieved on the rail network varies, according to Recordit, from $0 \%$ to $20 \%$, depending on the characteristics of the railway lines. In order to evaluate the sensitivity of the optimal locations to this parameter, the problem was solved for possible gains of $5 \%, 10 \%, 15 \%$ and $20 \%$. It outcomes that all the optimal locations obtained for all the configurations (from 2 to 10 hubs) remain the same. The optimal solutions can thus be considered as insensitive to these cost reductions, at least within the considered range of values.

Table 2

Optimal locations obtained with different minimum flow thresholds.

\begin{tabular}{lllll}
\hline$p$ & Threshold & & & \\
\cline { 2 - 5 } & 50,000 TEU & 75,000 TEU & 100,000 TEU & 125,000 TEU \\
\hline 2 & 1,2 & 1,16 & 1,14 & 4,8 \\
3 & $1,3,4$ & $1,3,4$ & $1,3,4$ & $1,2,11$ \\
4 & $1,2,5,6$ & $1,2,3,17$ & $1,2,9,14$ & $1,2,9,11$ \\
5 & $1,2,5,6,7$ & $1,2,5,6,7$ & $1,2,5,7,9$ & $1,2,5,9,11$ \\
6 & $1,2,3,4,5,6$ & $1,2,3,4,5,6$ & $1,2,5,7,9,14$ & $1,2,5,8,9,11$ \\
7 & $1,2,4,5,8,9,11$ & $1,2,3,4,5,6,18$ & $1,2,3,4,5,6,18$ & $1,2,3,4,5,7,8$ \\
8 & $1,2,4,5,8,9,10,11$ & $1,2,3,5,9,10,12,14$ & $1,2,4,5,6,12,13,14$ & $1,2,4,5,6,12,13,14$ \\
9 & $1,2,4,5,6,9,12,13,14$ & $1,2,4,5,6,9,12,13,14$ & $1,2,4,5,9,10,12,14,15$ & $1,2,4,5,9,10,12,14,15$ \\
10 & $1,2,4,5,6,9,12,13,14,15$ & $1,2,4,5,6,9,12,13,14,15$ & $1,2,4,5,6,9,12,13,14,15$ & $1,2,4,5,6,9,12,13,14,15$
\end{tabular}

1 London; 2 Paris; 3 Köln; 4 Lyon; 5 Milan; 6 Madrid; 7 Münster; 8 Namur; 9 Barcelona; 10 Hamburg; 11 Darmstadt; 12 Eindhoven; 13 Hannover; 14 Karlsruhe; 15 Munich; 16 Metz; 17 Marseille; 18 Nuremberg; 19 Lille; 20 Antwerp. 


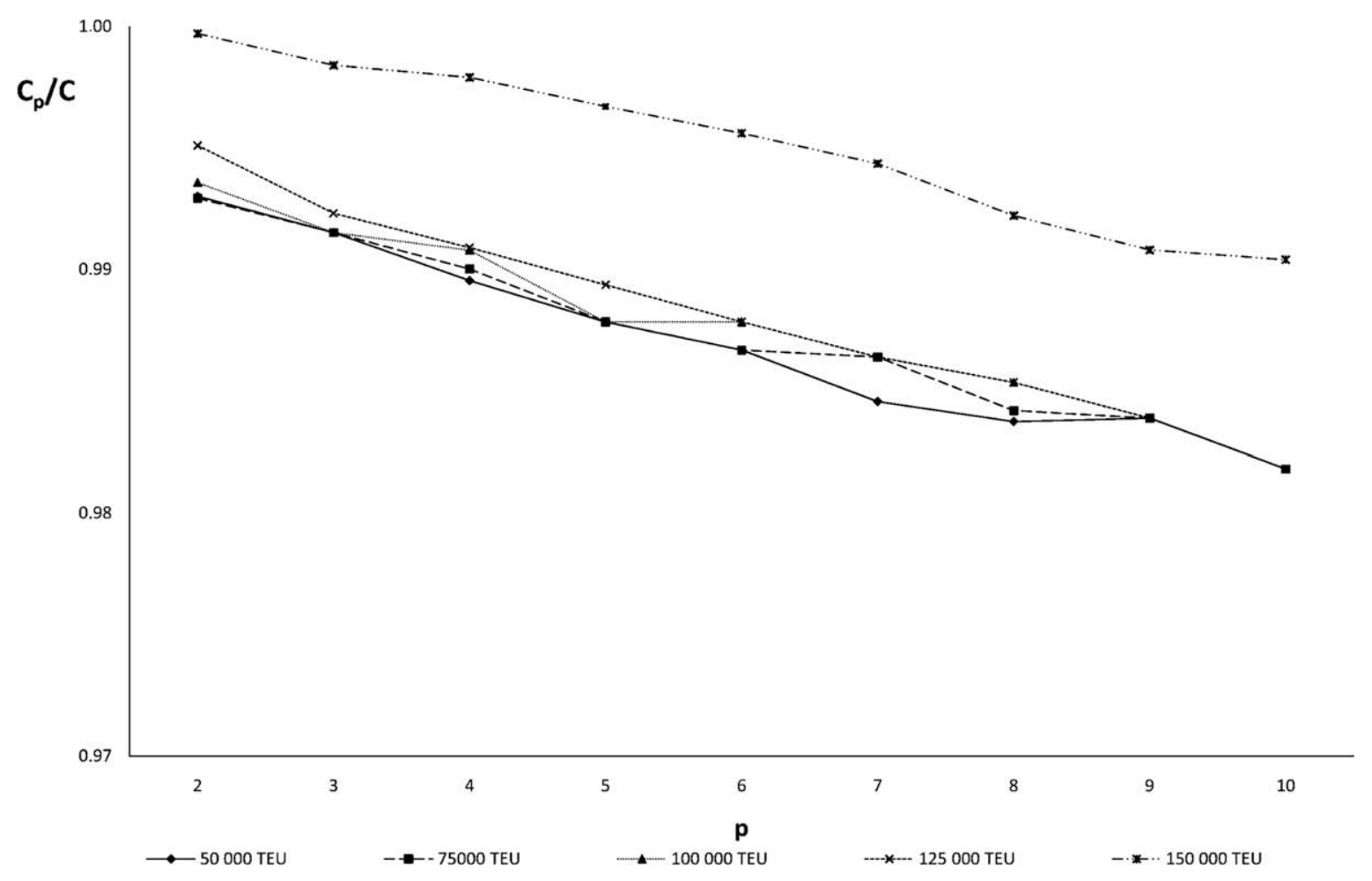

Fig. 3. Evolution of the total cost on the transportation system.

\subsection{Optimal configurations}

In Fig. 3, a local minimum was observed for $p=8$. Note that, in some configurations with $p \geqslant 10$, the total cost on the system can be lower than the one for the height-hub configuration. However, some terminal classifications like those published in Wiegmans (2003) or SIMET (1995) assume that the hubs must capture more than 100,000 ITU/yr.

A closer look to the number of ITUs captured by the hubs in our model reveals that, on an average basis, the optimally located hubs handle indeed more than 100,000 ITUs, the seven-hubs configuration yielding the highest capture. For the height- and nine-hub configurations, there are however two-hubs that capture only about 80,000 ITUs; it is the case for three terminals when ten hubs are located.

In the standard multiple-hubs network problem, it is assumed that all the hubs are connected directly to each other. Thus, if a network includes $N$ hubs, $N(N-1)$ inter-hub relations are needed. In our model, we observe that all the hub connections are indeed used for all the configurations up to six hubs, but four inter-hub connections (for a total of 21) are not used for the seven-hub configuration. This ratio becomes $4 / 28,7 / 36$ and $9 / 45$ for the configurations with 8,9 and 10 hubs, respectively. In other words, the solutions tend to correspond less to real hub-and spoke networks as $p$ increases.

These two reasons, added to the fact that a local minimum is observed for height-hubs in Fig. 3, suggest that, given our hypotheses, the upper limit for the number of container terminals embedded in a European hub-and-spoke network is height.

When the reference scenario (without terminals) is compared to the results obtained when trans-shipments at the seven international hubs mentioned by Ballis (2002) (including an additional hub in Milan) are made possible, our model estimates that road transport decreases by 1.16 bn ton-km/yr and that the total cost on the transportation system decreases by $0.22 \%$. Our optimal configuration with seven-hubs (Paris, Lyon, Milan, Barcelona, Darmstadt, London and Namur), as represented by Fig. 5, results in a decrease of 4.2 bn of ton- $\mathrm{km} / \mathrm{yr}$ transported by road, which represents $35 \%$ of the annual objective of the Marco Polo I programme. This configuration decreases the total cost by $1.54 \%$. In this optimal solution, intermodal transport is not competitive (and thus not used) on four inter-hub links (Paris/Darmstadt, Namur/Darmstadt, Paris/Namur and Milan/ Darmstadt, which are therefore not represented in Fig. 5). Note that intermodal transport can sometimes be competitive for distances that are only slightly longer than $300 \mathrm{~km}$, such as the Milan/Lyon relation.

One have to keep in mind that the improvements induced by hub-and-spoke networks are to be considered globally and that, at the local level, intermodal transport can generate additional trucking to and from the terminals, which are often located in already congested areas. Moreover, the average payload for pre- and post-haulages is lower than for traditional trucking (Recordit considers $65 \%$ instead of $85 \%$ for long haul trucking). In our optimal solution with seven-hubs, pre- 


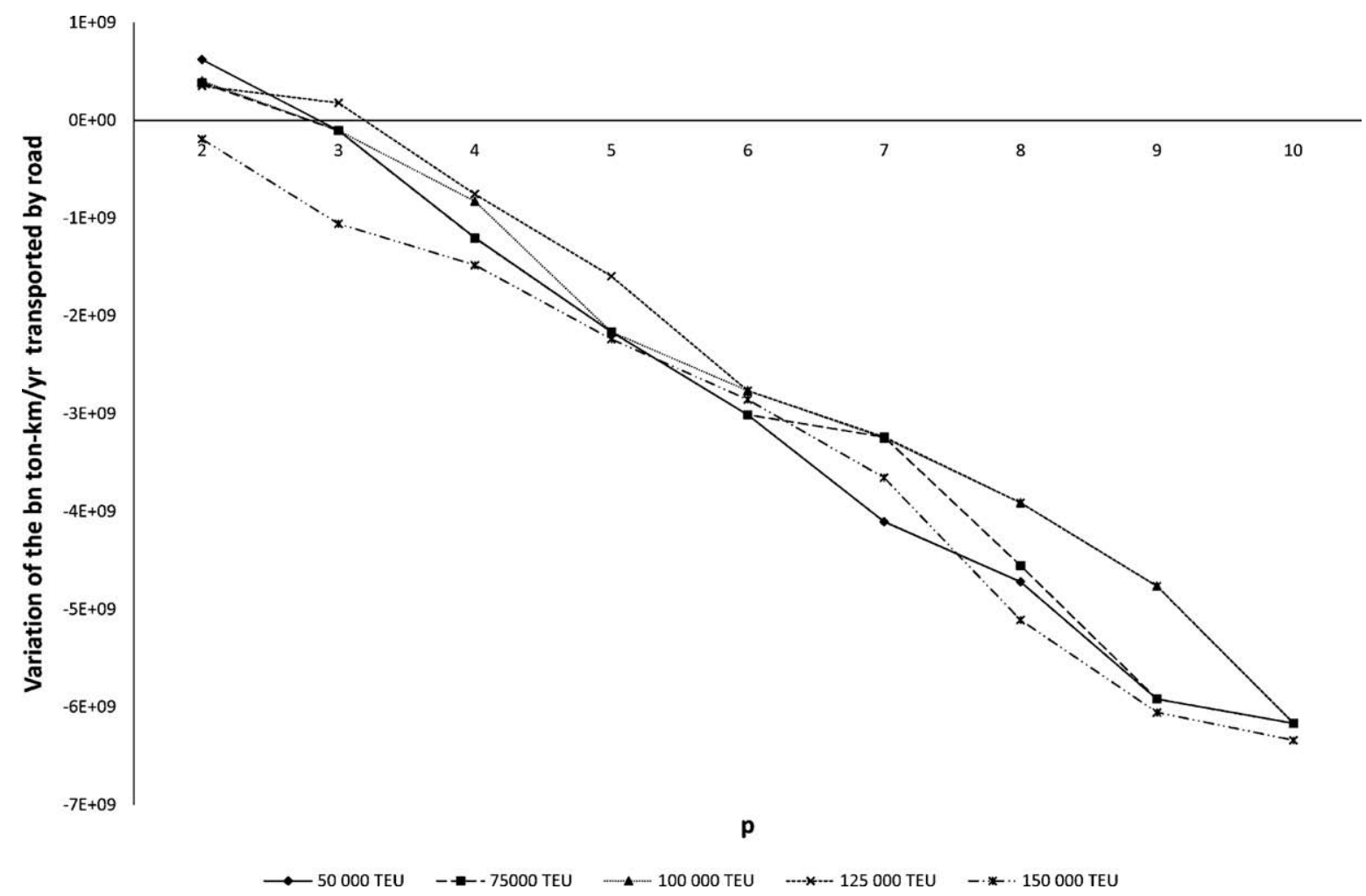

Fig. 4. Evolution of the ton-km transported by road.

and post-haulages represent 2 bn ton-km/yr. Despite this, the same optimal configuration yields for a reduction of 4.2 bn ton-km/yr for truck transport.

The heuristic solution obtained by Jeong et al. (2007) for a 10-countries European railway network was an eight-hub configuration (Karlsruhe, Munich, Nuremberg, Hamburg, Düsseldorf, Paris, Metz and Lyon). This configuration has only three hubs in common with our optimal configuration with the same number of hubs (Milan, Paris, Barcelona, Hamburg, Darmstadt, London, Namur and Lyon). This is due to the fact that most of their 48 potential locations were in France and Germany, with only one location in Belgium, the Netherlands, Poland, the Czech Republic, Austria and Switzerland, and three locations in the north of Italy while our model is based on 85 potential locations spread over a larger geographical area. Moreover, they only consider rail flows (and not the other modes) and their potential locations are chosen among the existing terminals. Finally, they estimate the economies of scale for each inter-hub relation according to the physical characteristics of the trains that are used and the service frequency. The results of their model are thus not easy to compare with ours.

\subsection{Optimal solution that takes the existing hubs into account}

The optimum locations for $p$ ' new hubs in a configuration that already contains $p$ " hubs ( $p=p^{\prime}+p$ ") can be calculated. If $J$ $(\subset N)$ is the set of existing hubs, the constraints $X_{i i}=1 \forall i \in J$ have to be added to the constraints (1.1-1.6).

If an additional hub were to be added to the configuration with seven-hubs described by Ballis (2002), it should be located in London. This would decrease road transport by $1.75 \mathrm{bn}$ ton-km/yr and the total transport cost by $1.33 \%$. This can be compared to our optimal configuration with eight-hubs that decreases road flows by 4.72 bn ton-km/yr and total cost by $1.63 \%$.

If two additional hubs were to be added, they should be located in London and in Madrid, decreasing road transport by $3.42 \mathrm{bn}$ ton- $\mathrm{km} / \mathrm{yr}$ and the total cost by $1.57 \%$. If three hubs were added, the road flow would decrease by 5.92 bn ton- $\mathrm{km} / \mathrm{yr}$ and the total cost by $1.61 \%$, which is still less than our optimal solution with eight-hubs.

\section{Concluding remarks}

Intermodal transport is one of the key elements towards a sustainable freight transport policy over medium and long distances. However, its efficiency strongly depends on the location of the container terminals. Several network topologies and types of terminals can be implemented, but policy makers don't have a complete set of adequate support tools that can help to take the right strategic decision at the trans-national level. Indeed, the decision to open a new terminal is most often taken 


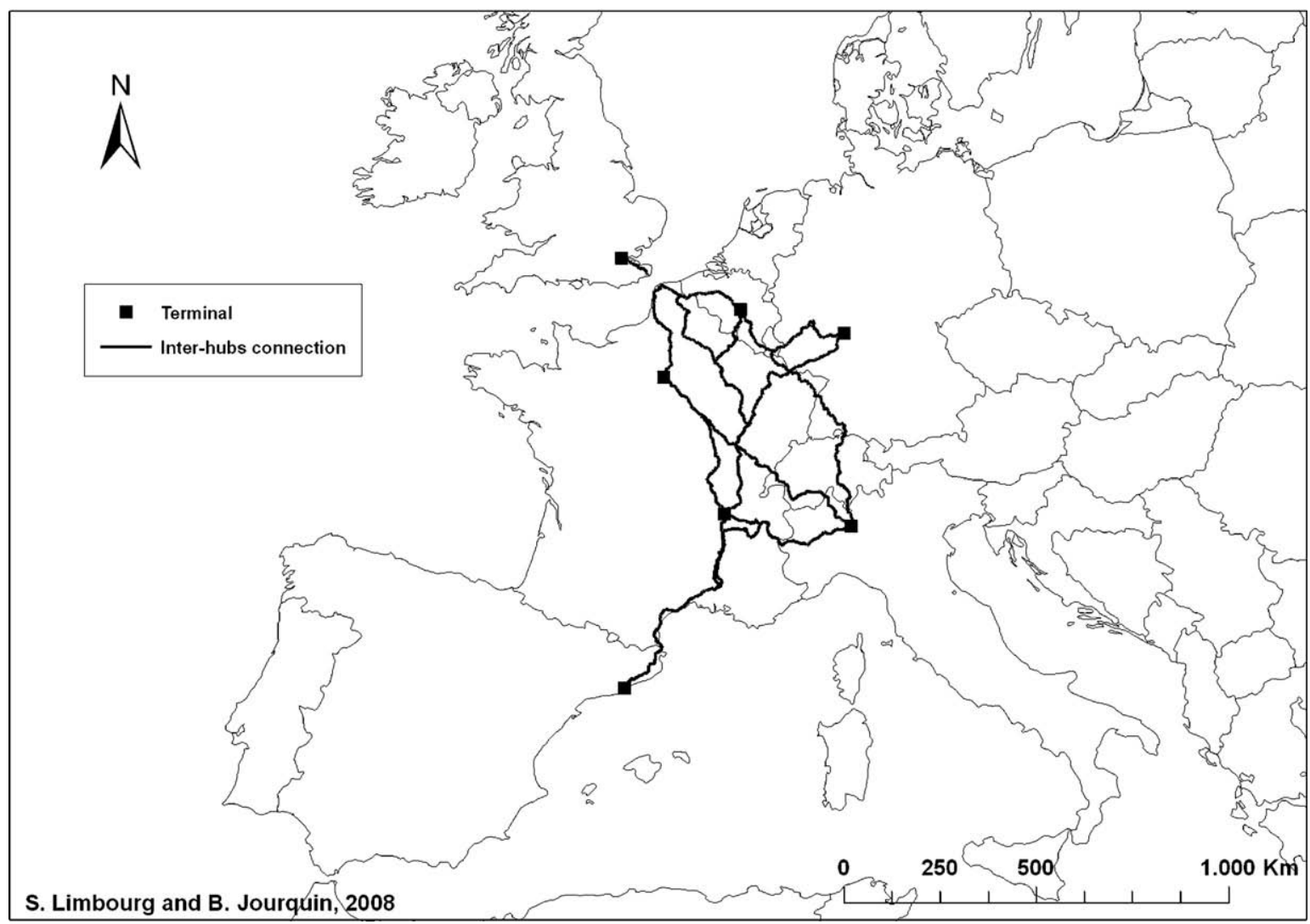

Fig. 5. Optimal configuration with seven-hubs.

at the national or even regional level, ignoring the international network effects. These local decisions can lead to a reduction of the global efficiency of the intermodal transportation system.

The methodology presented in this paper, and its computer implementation, offer an optimisation tool that can be used by policy makers in the framework of an international hub-and-spoke railway network that interfaces road and rail transport. The tool can compute the optimal locations of a given number of hubs or find out the best location(s) for one or more additional hubs, taking an existing configuration into account. The main contribution of the method is to propose an iterative procedure based on both the $p$-hub median problem and the multi-modal assignment problem. Moreover, the objective function of the formulation includes the costs for pre- and post-haulages by road, trans-shipment (according to the number of handled containers into account) and rail haulage.

It comes out that the locations of the current seven European hubs induce a sub-optimal hub-and-spoke network. Indeed, the performance of the optimal configuration that results from our model (for the same number of hubs) is more than three times better in terms of reduction of the ton.km/yr transported by road. This solution would achieve 35\% of the Marco Polo I annual objective. The model also predicts that no more than height-hubs should operate on the European network.

Obviously, the results depend on the quality of the used origin-destination matrices and the existence of other types of terminals, as their interaction with the hubs still remains to be considered and incorporated in the model. For instance, although all the traffic to and from the ports were taken into account, the port activities were not explicitly modelled. Therefore, an additional constraint could be added to the model formulation in order to locate the hubs at, at least, a given distance from a port. Further, no capacity constraints were considered on the railway network, although it is known that some chunks suffer from congestion.

Finally, we are aware that the second best configuration obtained for a given number of hubs can be very comparable, in terms of total costs, to the optimal solution. Therefore, local consideration such as ground availability or price could make the difference for decision makers.

\section{Acknowledgements}

We wish to thank NEA Transport Research and Training, and especially Pieter Hilferink, Research Director at the Institute, who allowed us to use their origin-destination matrices for European freight transport. The use of such a database contrib- 
uted greatly to the development of a credible case study. Thanks are due to anonymous referees who made very constructive comments, all errors remaining are ours.

\section{References}

Arnold, P., 2002. Localisations optimales, logique multi-réseaux et terminaux de transport multimodal: formalisation et applications. Ph.D. Thesis, Department of Geology and Geography, Catholic University of Louvain, Belgium.

Arnold, P., Marchand, H., Peeters, D., Thomas, I., 2002. Pour une localisation optimale des centres de transbordement entre réseaux de transport: formulation et extensions. The Canadian Geographer 45 (3), 427-436.

Arnold, P., Peeters, D., Thomas, I., 2004. Modelling a rail/road intermodal transportation system. Transportation Research Part E 40, 255-270.

Aykin, T., 1990. On a quadratic integer program for the location of interacting hub facilities. European Journal of Operational Research 46, 409-411.

Ballis, A., 2002. Innovative technologies for intermodal transfer points in inventory and expert system on new technologies in intermodal transport European. Community Project.

Ballis, A., Golias, J., 2002. Comparative evaluation of existing and innovative rail-road freight transport terminals. Transportation Research Part A 36, 593611 .

Bontekoning, Y.M., Macharis, C., Trip, J.J., 2004. Is a new applied transportation research field emerging? A review of intermodal rail-truck freight transport literature. Transportation Research Part A 38 (2004), 1-34.

Bowersox, D.J., Closs, D.J., Helfereich, O.K., 1986. Logistical Management. Macmillan Publishing Company, New York.

Campbell, J.F., 1994. Integer programming formulations of discrete hub location problems. European Journal of Operational Research 72 (2), 387-405.

Campbell, J.F., 1996. Hub location and the p-hub median problem. Operations Research 44 (6), 923-935.

Casillas, P.A., 1987. Data aggregation and the p-median problem in continuous space. In: Ghosh, A., Rushton, G. (Eds.), Spatial Analysis and LocationAllocation Models. Van Nostrand Reinhold Publishers, New York, pp. 327-344.

Comité National Routier - French Road National Committee, 2007. Available from: <http://www.cnr.fr/outils/prix_revient/index.phtml>.

Crainic, T.G., Florian, M., Guélat, J., Spiess, H., 1990. Strategic planning of freight transportation: stan an interactive graphic system. Transportation Research Record 1283, 97-124.

Current, J.R., Schilling, D.A., 1987. Elimination of source A and source B errors in p-median location problem. Geographical Analysis 19 (2), 95-110.

Current, J.R., Schilling, D.A., 1990. Analysis of errors due to demand data aggregation in the set covering and maximal covering location problems. Geographical Analysis 22, 116-126.

ECMT (European Conference of Ministers of Transport), 1998. The Current State of Combined Transport in Europe, OCDE, Paris.

Ernst, A.T., Krishnamoorthy, M., 1996. Efficient algorithms for the uncapacitated single allocation p-hub median problem. Location Science 4 (3), 139154.

Francis, R.L., Lowe, T.J., Rayco, M.B., 1996. Row-column aggregation for rectilinear distance p-median problems. Transportation Science 30 (2), 160 174.

Francis, R.L., Lowe, T.J., Rushton, G., Rayco, M.B., 1999. Aggregation methods for multi-facility location problems: Strategies for containing error. Geographical Analysis 31, 67-87.

Goodchild, M.F., 1979. The aggregation problem in location-allocation. Geographical Analysis 11 (3), $240-255$.

Harker, P.T., 1987. Predicting Intercity Freight Flows. VNU Science Press.

Jeong, S.-J., Lee, C.-G., Bookbinder, J.H., 2007. The European freight railway system as a hub-and-spoke network. Transportation Research Part A 41, 523536 .

Jourquin, B., Beuthe, M., 1996. Transportation policy analysis with a geographic information system: the virtual network of freight transportation in Europe Transportation Research Part C: Emerging Technologies 4 (6), 359-371.

Jourquin, B., Limbourg, S., 2006. Equilibrium traffic assignment on large virtual networks: implementation issues and limits for multi-modal freight transport. European Journal of Transport and Infrastructure Research 6 (3), 205-228.

Jourquin, B., 2006. A multi-flow multi-modal assignment procedure on large freight transportation networks. Studies in Regional Science 35, 929-946.

Klincewicz, J.G., 1991. Heuristics for the p-Hub location problem. European Journal of Operational Research 53, $25-37$.

Klincewicz, J.G., 1992. Avoiding local optima in the p-hub location problem using tabu search and GRASP. Annals of Operations Research 40, 283-302.

Limbourg, S., Jourquin, B., 2007. Rail-road terminal locations: aggregation errors and best potential locations on large networks. European Journal of Transport and Infrastructure Research 7 (4), 317-334.

Limbourg, S., 2007. Planification stratégique de systèmes de transport de marchandises en Europe: modèles de localisations optimales de hubs de conteneurs sur un réseau multimodal. Ph.D. Thesis, Louvain School of Management - FUCaM - Mons Campus, Belgium.

Macharis, C., 2004. A methodology to evaluate potential locations for intermodal barge terminals: a policy decision support tool. In: Beuthe, M., Himanen, V., Reggiani, A. (Eds.), European Strategies in the Globalising Markets.

O'Kelly, M., 1987. A quadratic integer program for the location of interaction hub facilities. European Journal of Operational Research 32, 393-404.

O'Kelly, M.E., 1992. A clustering approach to the planar hub location problem. Annals of Operations Research 40, $339-353$.

O’Kelly, M., Miller, H., 1994. The hub network design problem: a review and synthesis. Journal of Transport Geography 2 (1), $31-40$.

O'Kelly, M.E., Bryan, D., Skorin-Kapov, D., Skorin-Kapov, J., 1996. Hub network design with single and multiple allocation: a computational study. Location Science 4 (3), 125-138

O'Kelly, M.E., Skorin-Kapov, D., Skorin-Kapov, J., 1995. Lower bounds for the hub location problem. Management Science 41, 713-721.

Plastria, F., 2001. On the choice of aggregation points for continuous p-median problems: a case for the gravity center. TOP 9, 217-242.

PINE, 2004. Prospects of Inland Navigation in an Enlarged Europe. <http://europa.eu.int/comm/transport/iw/prospect/index_fr.htm>.

Racunica, I., Wynter, L., 2005. Optimal location of intermodal freight hubs. Transportation Research Part B 39, $453-477$.

Recordit, 2002. REal COst Reduction of Door-to-door Intermodal Transport. <http://www.recordit.org/>.

Sheffi, Y., 1985. Urban Transportation Networks: Equilibrium Analysis with Mathematical Programming Methods. Prentice-Hall, Englewood Cliffs, New Jersey.

SIMET project, 1995. Future Optimum Terminals for Intermodal Transport, Doc. Euret/411/95, Brussels.

Skorin-Kapov, D., Skorin-Kapov, J., 1994. On tabu search for the location of interacting hub facilities. European Journal of Operational Research 73, 502509.

Skorin-Kapov, D., Skorin-Kapov, J., O’Kelly, M.E., 1996. Tight linear programming relaxation of uncapacitated p-hub median problems. European Journal of Operational Research 94, 582-593.

Smith, K., Krishnamoorthy, M., Palaniswami, M., 1996. Neural versus traditional approaches to the location of interacting hub facilities. Location Science 4 (3), 155-171.

Stratec, S.A., ADE and F.U.CaM.-G.T.M., 1999. Plan multimodal de transport de marchandises de la Région Wallonne, phase III. Analyse Prospective à l'horizon 2010, MET.

Tavasszy, L., 1996. Modelling European Freight Transport Flows. Ph.D. Thesis, Technical University of Delft, The Netherlands.

Terminet, 1996. Technical Annex. University of Technology, Delft. November.

Terminet, 1997a. Innovative Bundling Network Concepts in Europe. University of Technology, Delft.

Terminet, 1997b. Quality Jump in Intermodal Transport: Theory and Practice. University of Technology, Delft. July.

Vervoort, K., Split, W., 2005. Economische toets variant 3: betalen per kilometer vracht. Ministerie van Verkeer en Waterstaat. 
Wiegmans, B., 2003. Performance conditions for container terminals. Ph.D. Thesis, Vrije University, Amsterdam.

Wiegmans, B., Masurel, E., Nijkamp, P., 1999. Intermodal freight terminals: an analysis of the terminal market. Transportation Planning and Technology 23 , 105-128.

Zhao, P., Batta, R., 1999. Analysis of centroid aggregation for the euclidean distance p-median problem. European Journal of Operational Research 113 (1), 147-168.

Zhao, P., Batta, R., 2000. An aggregation approach to solving the network p-median problem with link demands. Networks 36, $233-241$. 